AUdiology

\title{
Transtympanic Hearing Aid: exploratory study on a new device
}

\author{
Transtympanic Hearing Aid: studio preliminare con nuova protesi \\ S. BERRETTINI ${ }^{1}$, L. BRUSCHINI ${ }^{1}$, A. DE VITO ${ }^{1}$, T. GNOCCO ${ }^{2}$, N.C. ROSICA ${ }^{3}$, L. PIZZOLI ${ }^{4}$, F. FORLI \\ ${ }^{1}$ ENT Audiology and Phoniatric Unit, University Hospital of Pisa, Pisa, Italy; ${ }^{2}$ CRAI S.p.A., Bovolenta, Italy; ${ }^{3}$ ENT \\ freelance doctor, Rome, Italy; ${ }^{4}$ Engineer freelance, Rome, Italy
}

\begin{abstract}
SUMMARY
In this paper, we present the preliminary results achieved with a transtympanic hearing aid (THA). This is a modified digital, open-fit external hearing aid (HA) designed for acute study only, which allows coupling with a pre-implanted ventilation tube. The THA conveys amplified sound directly onto the round window, bypassing the ossicular chain, in contrast with traditional HAs that convey sound onto the second or third portion of the external auditory canal. The THA has been developed as an alternative to standard HAs and active middle ear implants for patients who are unsatisfied with traditional HA outcomes and want to avoid middle-ear implantation. The results achieved using the THA were compared to those obtained with an equivalent device, the Latitude 8 Moxi 13 (Moxi), uncoupled from the ventilation tube, and placed onto the outer ear. For this purpose, 12 patients with conductive (1/12), sensorineural (3/12), or mixed (8/12) hearing loss from moderate to severe, with a pre-implanted ventilation tube, underwent audiological evaluation with both the THA and the Latitude 8 Moxi 13 (Moxi). Our initial results showed that the THA provided significant improvement in the warble tone results in comparison to the Moxi. Moreover, patients with a PTA between 41 and 90 also achieved better results in terms of speech recognition using the THA in comparison to the Moxi. In conclusion, these outcomes provide the first evidence of the potential benefits of the THA over standard open-fit HAs. Nevertheless, these preliminary outcomes require further confirmation.
\end{abstract}

KEY WORDS: Transtympanic hearing aid $\bullet$ Sound conveying $\bullet$ Hearing loss $\bullet$ Round window

\section{RIASSUNTO}

Nel presente articolo vengono riportati i risultati preliminari ottenuti con l'apparecchio acustico Transtympanic Hearing Aid (THA). Il THA è una protesi acustica digitale, open-fit modificata, sviluppata per studi clinici in acuto e ideata per essere accoppiata a un drenaggio trans-timpanico, precedentemente posizionato, con lo scopo di inviare il suono amplificato direttamente all'orecchio medio e alla finestra rotonda, bypassando la catena ossiculare. Il dispositivo THA rappresenta una possibile alternativa sia alle protesi acustiche tradizionali, sia alle protesi attive di orecchio medio, per pazienti con risultati insoddisfacenti con protesi acustiche tradizionali, evitando la chirurgia di impianto di protesi di orecchio medio. I risultati ottenuti con la THA sono stati confrontati con quelli ottenuti con un device equivalente, una protesi acustica tradizionale, open-fit, non accoppiata al drenaggio trans-timpanico, la Latitude 8 Moxi 13 (Moxi). Con questo scopo, 12 pazienti affetti da ipoacusia trasmissiva (1/12), neurosensoriale (3/12) o mista (8/12), di entità da moderata a grave, nei quali era stato precedentemente posizionato un drenaggio trans-timpanico, sono stati sottoposti ad una valutazione audiologica sia con il dispositivo THA che con il Moxi. I risultati preliminari hanno dimostrato che la protesi acustica THA ha consentito di raggiungere risultati, in termini di soglia audiometrica in campo libero con device in funzione, significativamente superiori a quelli conseguiti con la protesi Moxi; inoltre usando la protesi THA anche i risultati in termini di percezione verbale sono stati migliori, soprattutto nei pazienti con PTA tra 41 e $90 \mathrm{~dB}$. I risultati preliminari presentati, offrono una iniziale evidenza dei benefici potenzialmente offerti dall'uso del dispositivo THA, rispetto alle protesi acustiche tradizionali. Tuttavia questi dati devono essere confermati da studi ulteriori su un più ampio numero di pazienti.

PAROLE CHIAVE: Transtympanic hearing aid $\bullet$ Trasmissione sonora $\bullet$ Perdita di udito $\bullet$ Finesra rotonda

Acta Otorhinolaryngol Ital 2018;38:236-241

\section{Introduction}

Hearing aids (HAs) improve verbal discrimination and thus interpersonal communication in patients suffering from mild to moderate hearing loss (HL) ${ }^{1}$. Nonetheless, up to $40 \%$ of patients with HA indication report that they can either not use the prescribed HA or gain sufficient benefit from it ${ }^{2}$.

This reduced acceptance is mostly linked to typical HA drawbacks, such as feedback, signal distortion, occlusion 
effect, inadequate amplification of the high frequencies and limited compatibility with outdoor activities. Furthermore, diseases such as chronic otitis media, infections of the external auditory canal (EAC) or a stenotic EAC may limit the effectiveness of the HAs ${ }^{3}$. Also, invasive ear surgeries, such as radical mastoidectomy or ossiculoplasty severely limit the potential benefits of HAs. The current alternative to HAs in these cases is surgical placement of an active middle ear implant (AMEI), which is however far more expensive and invasive than a HA ${ }^{4}$. Accordingly, this is generally not an option for patients without financial support.

The transtympanic hearing aid (THA) described in this paper has been developed as an alternative to standard HAs and AMEIs if the patient is unsatisfied with HA outcomes, but who does not want to undergo middle ear implantation. The THA is a modified digital open-fit HA designed to allow coupling with a pre-implanted ventilation tube. The THA conveys the amplified sound directly onto the round window bypassing the ossicular chain, in contrast with traditional HAs that convey sound onto the second or third portion of the EAC. This configuration is expected to reduce distortion and improve the gain in a wider frequency range in comparison with standard HAs. The study described herein is the first attempt to evaluate this device in patients with different types of HL considering sound perception in the audible frequency range and in terms of speech recognition.

\section{Materials and methods}

The aim of the study is to provide initial assessment on the performance of a new THA (investigational medical device): the results obtained by patients while using the THA, connected to the ventilation tube, were compared with those obtained by the same patients using the Latitude 8 Moxi 13 HA (Moxi), which is considered as a comparator in the present study.

The study group was composed of 15 subjects between 39 and 74 years diagnosed with mild to severe post-lingual HL of conductive (1/15), sensorineural (4/15), or mixed $(10 / 15)$ origin. Subjects were eligible only if they had not been wearing a HA in the last 2 years and have been previously implanted with a ventilation tube in the ear to be tested for medical purposes. In 7/12 patients, the ventilation tube was placed in the posterior inferior quadrant and in $5 / 12$ patients in the anterior inferior quadrant of the tympanic membrane. All enrolled patients were fluent in Italian. Detailed information about the study population is provided in Table I.

This was an exploratory, two-arm, randomised, crossover, cross-sectional, monocentric (Pisa, Italy), comparative study. The subjects did not know if they were wearing
Table I. Characteristics of the tested population.

\begin{tabular}{lcc} 
Enrolment characteristics & No. & $\%$ \\
Subjects enrolled in the study & 15 & 100 \\
Subjects who completed the study & 12 & 80 \\
Withdrawals & 3 & 20 \\
Mean age: 63 years & & \\
Mean HL duration: 29 years & & \\
Gender & 7 & 58.3 \\
Female & 5 & 41.7 \\
Male & & \\
Tested ear & 6 & 50 \\
Right & 6 & 50 \\
Left & & \\
Aetiology & 11 & 73.3 \\
COM & 1 & 6.7 \\
Ménière's disease & 2 & 13.3 \\
Tympanosclerosis + COM & 1 & 6.7 \\
Stapes ossification + COM & 10.4 \\
Type of HL & 10 & 6.3 \\
Mixed & 4 & 26.6 \\
Sensorineural & 1 & \\
Conductive & & \\
HA experience & 10.7 \\
None & & \\
5 year & & \\
\hline
\end{tabular}

the THA or the Moxi, and the statistician performing data analysis did not receive information about the type of HA was under evaluation. According to the cross-over design of the study, subjects were randomised with the freeware "Research Randomizer" (https://www.randomizer.org/) in Arm 1, where they were tested first with the THA and then with the Moxi; and in Arm 2, where they were tested first with the Moxi and then with the THA. The wash-out period between the two testings with either device was 1 hour.

The study included a one-off visit to the clinic with 3 consecutive sessions. In the first session (screening), the subject's medical and audiological history were recorded. In addition, a general physical examination was performed as well as otomicroscopy to assess middle ear status and verify the position of the ventilation tube. This session also included pure tone audiometry (PTA; Interacoustics Clinical Audiometer AC40) in a sound-treated room at 0.25-0.51-2-3-4-8 KHz and assessment of air conduction thresholds at the same frequencies. Bone conduction thresholds were assessed at $0.25-0.5-1-2-4 \mathrm{KHz}$. The second and third sessions (testing) were used to evaluate either the THA and 
then the Moxi or vice-versa, according to the cross-over design described above. At the beginning of each session evaluating the THA, the latter was connected to the preimplanted ventilation tube under otomicroscopy and the patient was fitted with BEM-ONE FIT-BOSS-PRO (CRAI S.p.A., Italy). At the beginning of each session evaluating the Moxi, the latter was placed behind the ear (BTE) and the pre-implanted ventilation tube temporally closed under otomicroscopy. At this point, the patient was fitted with Auto Pro 2 software (Unitron, U.S.). Upon fitting with either HA, the patient was given a 40 min adaptation period before being tested. Each subject underwent PTA in free field with warble tone and was asked to perform a disyllabic word and an adult sentence test depending on the study arm they had been assigned to, according to the randomisation matrix. According to the cross-over design of the study, subjects were randomised with the freeware "Research Randomizer" (https://www.randomizer.org/) in Arm 1, where they were tested first with the THA and then with the Moxi; and in Arm 2, where they were tested first with the Moxi and then with the THA.

Warble tone thresholds were obtained at $0.25,0.5,1,2$, 3 and $4 \mathrm{kHz}$ in sound field. The subject was placed at $0^{\circ}$ azimuth to the speaker. The disyllabic word test was conducted in sound field at $65 \mathrm{~dB}$ SPL, with the subject positioned at $0^{\circ}$ azimuth to the speaker. Lists of 50 words extracted from "Audiometria Vocale, Volume II, CD 1, GN ReSound Italy S.r.l.” were presented. Track 12 was used in the first and Track 13 in the second of the 2 subsequent tests in Arm 1 and Arm 2. The adult sentence test was conducted in a sound field at $65 \mathrm{~dB}$ SPL, with the subject positioned at $0^{\circ}$ azimuth to the speaker. Lists of 20 sentences extracted from "Audiometria Vocale, Volume II, CD 2, GN ReSound Italy S.r.l." were presented. Track 12 was used in the first and Track 13 in the second of the 2 subsequent tests in Arm 1 and Arm 2. Positive score was counted only when the entire sentence was repeated correctly. In all the tests performed in free field, supra-aural earphones (TDH 39P CA50252 Telephonics 296D000-1) were used to mask the nontested ear.

\section{Evaluated devices}

The THA is manufactured by CRAI S.p.A. and consists of an open-fit external HA modified to be coupled, via a connection tube, with the pre-implanted ventilation tube. The Moxi (comparator) is manufactured by Unitron and distributed in Italy by CRAI S.p.A. It is a standard digital open-fit HA. The two HAs have the same technical characteristics (Fig. 1).

\section{Statistical analysis}

Subject characteristics and outcome variables were analysed with IBM SPSS statistics software (Version 21, IBM, NY, USA). Paired T-test for independent variables was used to compare the results with the THA vs. the Moxi. Pearson correlation coefficient was used to evaluate correlation between independent variables. All p-values are results of two-sided tests, and a level of significance was set at $\mathrm{p}<0.05$.

\section{Ethical considerations}

Informed consent and approval by the Ethics Committee (Approval n. 3429) was obtained prior to initiation. The study complied with applicable good clinical practice (GCP) guidelines and the Declaration of Helsinki.

\section{Results}

$12 / 15(80 \%)$ subjects completed the study. One subject was withdrawn because the ventilation tube was not correctly placed, one subject was withdrawn as unable to undergo the testing because of a suppurating ear and one subject was withdrawn as unable to wear the supra-aural earphone without discomfort.

PTA was performed during the screening session and the results are shown in Table II. The PTA at $0.5,1$, and $2 \mathrm{kHz}$ air conduction thresholds rounded to the nearest integer was $63 \mathrm{~dB}$.

Warble tone analysis showed a statistically significant improvement $(\mathrm{p}<0.05)$ with the THA vs. the Moxi only at $0.25,0.5,1$ and $4 \mathrm{kHz}$. A graphical representation of the results is depicted in Figure 2.

The analysis of the disyllabic word recognition results showed no statistically significant difference $(\mathrm{p}=0.16)$ in performance with the THA and Moxi (Fig. 3). However, when the disyllabic word recognition results were scattered against subjects' PTA, it was observed that in $8 / 9$ $(88.9 \%)$ of subjects with a PTA between 41 and $90 \mathrm{~dB}$ word recognition was between $80 \%$ and $100 \%$ when wearing the THA, while only $5 / 9(55.6 \%)$ obtained the same results with the Moxi (Table III). The analysis of the sentence comprehension test showed a trend towards a significant improvement $(p=0.06)$ when the THA was compared with the Moxi (Fig. 3).

\section{Discussion}

This paper describes the first testing of the THA in humans, which has been designed to bypass the ossicular chain and directly stimulate the round window. Our initial results showed that the use of the THA provided a significant improvement 


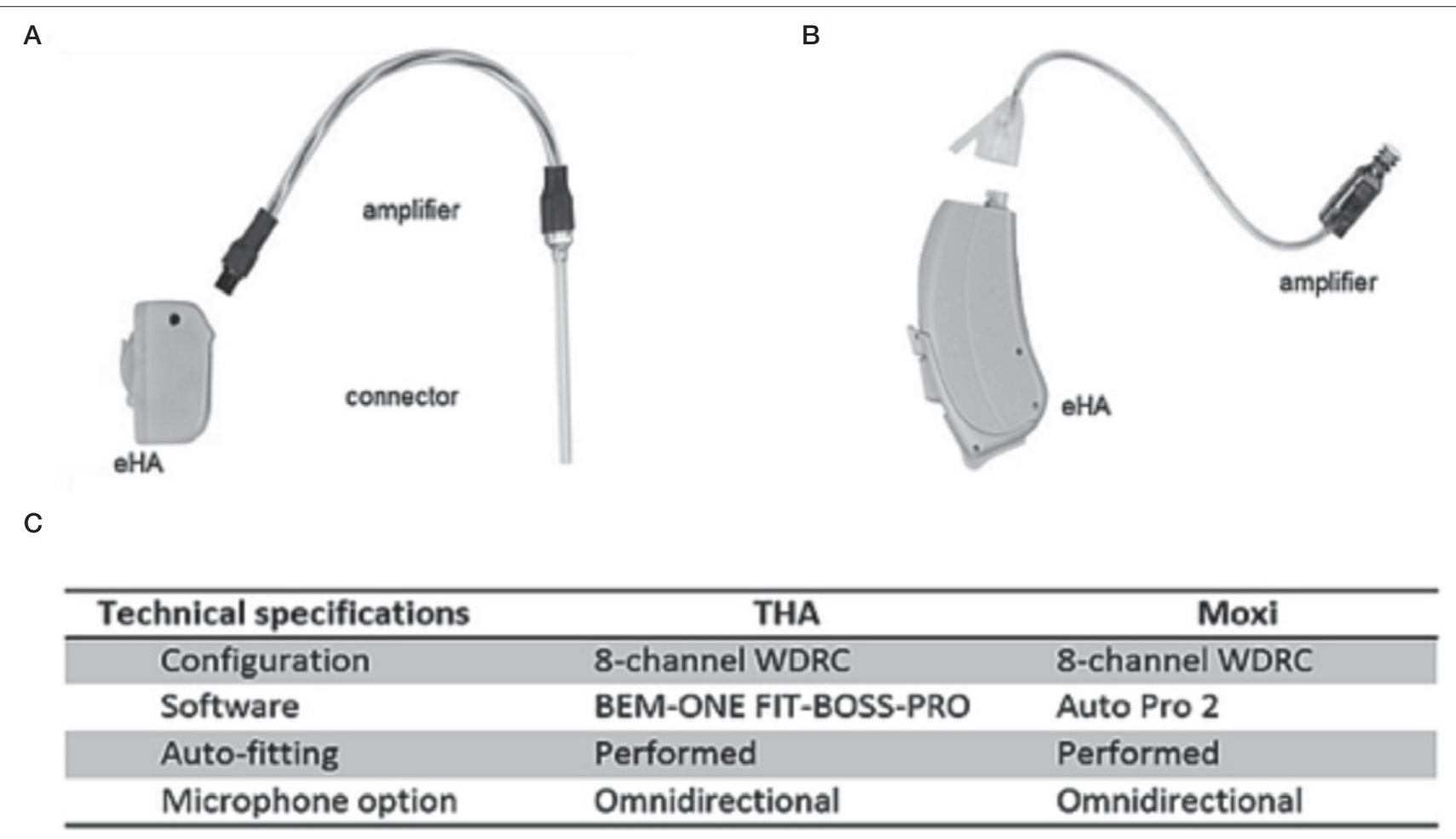

Fig. 1. A) THA components: external HA, amplifier and connector to which the ventilation tube is coupled; B) Moxi components: external HA and amplifier; C) Summary of technical specifications of the THA and Moxi.

in the warble tone results in almost all of the frequencies tested - an outcome that could not be achieved with the Moxi. This improvement was supported by the finding that when wearing the THA, $88.9 \%$ of the patients with a PTA between 41 and 90 understood between $80 \%$ and $100 \%$ of the words presented, while only $55.6 \%$ of the same patients obtained the same results when wearing the Moxi. Accordingly, these outcomes provide the first evidence of the potential benefits of the THA over standard open-fit HAs.

To our knowledge, no other HA similar to the THA is currently being investigated in clinical trials or available on the market. However, the principle behind the development of the THA, i.e. the idea of bypassing the ossicular chain and directly stimulating the round window is not new and has been thoroughly evaluated in the context of implantable and semi-implantable HAs ${ }^{5-7}$. In particular, Colletti et al., in 2006, underlined the possibility to directly stimulate the round window by placing the floating mass transducer (FMT) of the Vibrant Soundbridge (VSB) implant on the round window niche, bypassing the transmission apparatus of the middle ear. The authors reported good results both in terms of audiometric threshold and word discrimination in 7 patients with severe conductive and mixed hearing loss, demonstrating that direct stimu- lation of the round window is an effective treatment for patients with those characteristics ${ }^{6}$. In 2010, a European multicentre study concluded that direct stimulation of the round window by the FMT of the VSB device represents a safe and effective treatment for adults with conductive and mixed hearing losses ${ }^{8}$. More recently, Colletti et al. (2013) reported on the long-term safety and efficacy of this procedure in a larger series (50 patients) with moderate to severe mixed hearing loss ${ }^{7}$. The potential benefits of the THA over the abovementioned implantable and semi-implantable HAs are its reduced invasiveness, ease of the medical procedure and short time it requires as well as the limited costs for patients.

The study was performed within a limited sample size, including patients with different aetiologies and types of hearing loss. Consequently, it is not possible to generalise the results or consider the hearing loss characteristics as potential predictors for the effectiveness of THA use in comparison with a standard HA.

Another factor that strongly limits the generalisation of the observed results is the THA itself, which is a prototype, was designed exclusively for acute testing rather than for chronic implantation. Accordingly, the testing was "acute" and therefore unable to provide long-term 
Table II. PTA results presented as mean values with standard deviation. $\mathrm{N} / \mathrm{A}=$ not applicable.

\begin{tabular}{lcc}
$\begin{array}{l}\text { Tested frequency } \\
\text { (in kHz) }\end{array}$ & $\begin{array}{c}\text { Bone conduction } \\
\text { (in dB) }\end{array}$ & $\begin{array}{c}\text { Air conduction } \\
\text { (in dB) }\end{array}$ \\
\hline 0.25 & $17.72 \pm 10.74$ & $57.50 \pm 21.65$ \\
0.5 & $31.67 \pm 15.59$ & $56.67 \pm 23.48$ \\
1 & $35.83 \pm 16.93$ & $65.42 \pm 23.13$ \\
2 & $48.33 \pm 14.62$ & $67.50 \pm 19.09$ \\
3 & $\mathrm{~N} / \mathrm{A}$ & $72.33 \pm 16.58$ \\
4 & $45.45 \pm 16.44$ & $79.17 \pm 16.18$ \\
8 & $\mathrm{~N} / \mathrm{A}$ & $90.50 \pm 11.50$ \\
\hline
\end{tabular}

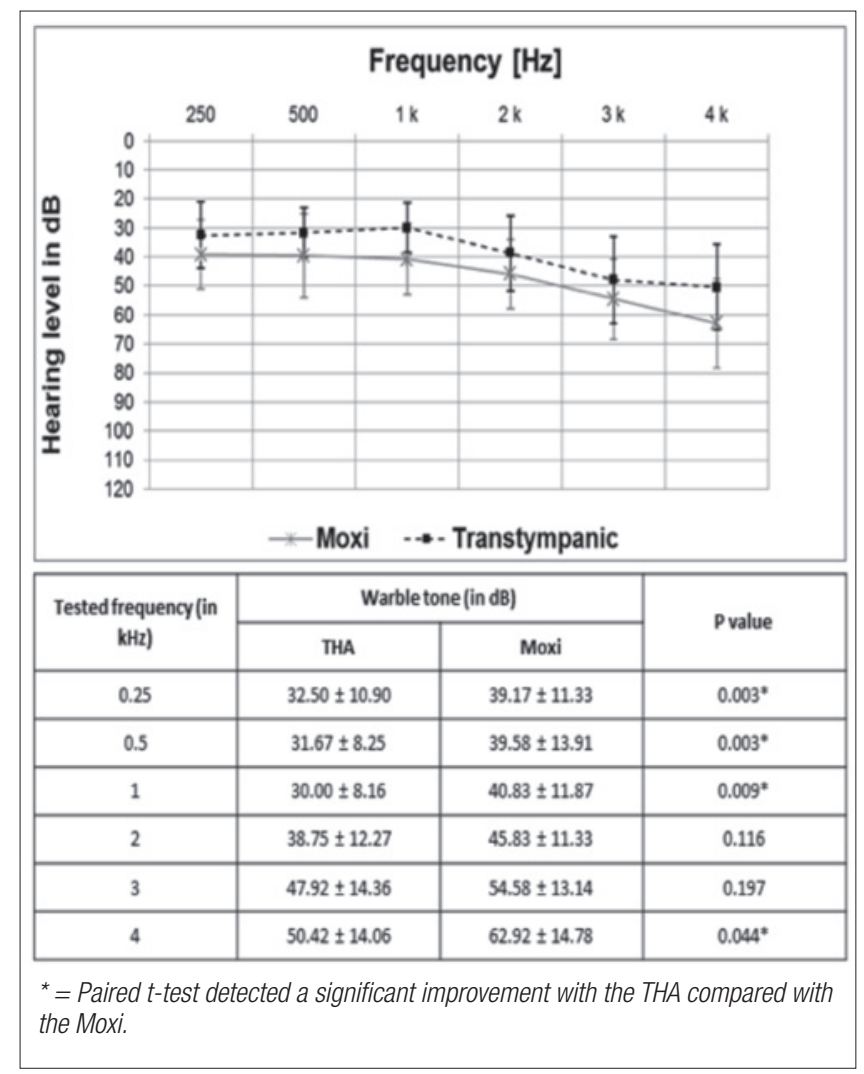

Fig. 2. Above: Mean scores of the warble tone thresholds (in $\mathrm{dB}) \pm$ standard deviation obtained with the THA and the Moxi. Below: All warble tone results presented as mean values with standard deviation. Paired t-test for independent variables was used to test comparisons between the two hearing aid performances.

results that could confirm the benefits of wearing a THA in real life conditions. Based on these considerations, confirmation of our results should be assessed in longterm studies with more homogeneous and larger cohorts of patients. Both THA and MOXI were fitted based on the respective default parameters, which were minimally different from each other. Thus, we believe they may have

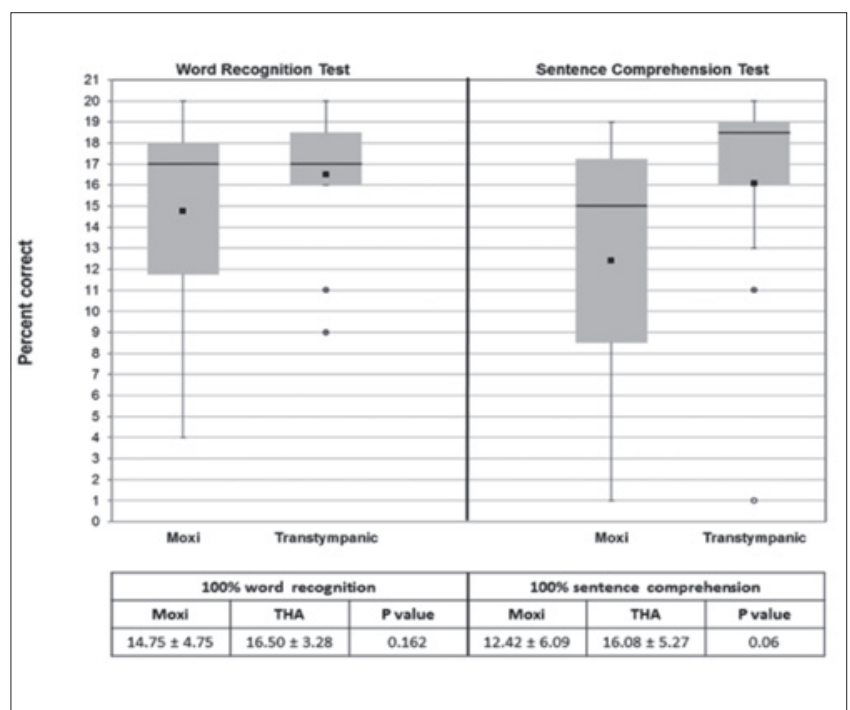

Fig. 3. Above: Word recognition and sentence comprehension test results. The data are displayed as "Box and Whisker" plots, with the mean depicted as black quadrats and the median as horizontal lines. The black circles represent outliers. Only words and sentences repeated by the subjects $100 \%$ correctly were considered as positive results. Below: Results of the word recognition and sentence comprehension tests with the THA and with the Moxi. All results are presented as mean values with standard deviation. Paired t-test for independent variables was used to test comparisons between the THA and Moxi performance.

had a reduced impact, if any, on the comparison between the results obtained with the two hearing aids.

Considering the promising results of this study, the next steps regarding the THA project include the development of a device for chronic implantation that should be tested to determine whether it is able to guarantee clinically significant acoustic gain, e.g. beneficial modification of the high frequencies $(\geq 2 \mathrm{kHz})$ spectrum. In this respect, the clinical testing of the THA will be performed in larger cohorts of patients with more homogeneous characteristics in terms of aetiology and type of hearing loss.

\section{Conclusions}

In agreement with the literature, the results of our study indicate that the direct stimulation of the middle ear and round window may offer advantages over traditional acoustic stimulation. However, the true significance of our results is not yet clear. Although the results of the warble tone are encouraging and to some extent supported by the word and sentence recognition test, the design of our study does not allow drawing generalised conclusions, both because of the limited and heterogeneous study population and the development stage of the THA. Moreover, we can speculate that benefits may be in relation to the 
Table III. Scattering of word recognition results in percentage ( $x$-axis) vs. PTA3 (y-axis). The numbers are the subjects' ID (T=word recognition percentage with the subject's wearing the THA; $M=$ word recognition percentage with the subject's wearing the Moxi).

\begin{tabular}{|c|c|c|c|c|c|c|c|c|c|c|c|}
\hline \multirow[t]{12}{*}{ PTA3 (dB) } & \multicolumn{11}{|c|}{ Word Recognition Percentage } \\
\hline & & $100-90$ & $89-80$ & $79-70$ & $69-60$ & $59-50$ & $49-40$ & $39-30$ & $29-20$ & $19-10$ & $09-0$ \\
\hline & $0-10$ & & & & & & & & & & \\
\hline & $11-20$ & & & & & & & & & & \\
\hline & $21-30$ & & & & & & & & & & \\
\hline & $31-40$ & $\begin{array}{l}7 \mathrm{~T} \\
7 \mathrm{M}\end{array}$ & $\begin{array}{l}1 \mathrm{~T} \\
1 \mathrm{M}\end{array}$ & & & & & & & & \\
\hline & $41-50$ & $\begin{array}{c}11 \mathrm{~T} \\
11 \mathrm{M} \\
13 \mathrm{M}\end{array}$ & 13T & & & & & & & & \\
\hline & $51-60$ & $10 \mathrm{~T}$ & & $10 \mathrm{M}$ & & & & & & & \\
\hline & $61-70$ & $8 \mathrm{M}$ & $\begin{array}{l}5 T \\
8 T\end{array}$ & & $5 \mathrm{M}$ & $6 \mathrm{~T}$ & $6 \mathrm{M}$ & & & & \\
\hline & $71-80$ & $2 \mathrm{~T}$ & $\begin{array}{l}2 M \\
3 T\end{array}$ & & & & & & $3 \mathrm{M}$ & & \\
\hline & $81-90$ & $\begin{array}{l}9 \mathrm{M} \\
9 \mathrm{~T}\end{array}$ & & & & & & & & & \\
\hline & $>91$ & & & & & $14 \mathrm{M}$ & 14T & & & & \\
\hline
\end{tabular}

type of hearing loss and that the greatest benefits can be achieved in cases with mixed hearing loss, due to conductive deficits (e.g. tympanosclerosis). As a consequence, it seems that possible candidates for the THA device may be patients with chronic otitis media or tympanosclerosis, with moderate-to-severe mixed hearing loss, who can only to a limited extend benefit from traditional hearing aids, including open-fit.

Further, larger studies with more homogeneous populations may help to determine the true effectiveness of the THA and the best target population for its future clinical use.

\section{Acknowledgements}

We would like to thank Dr. Edda Amann for the statistical analysis and Julia Messner for her support in medical writing. Furthermore, we would like to thank all colleagues from the departments involved in the collection of data.

\section{References}

1 Cox RM, Johnson JA, Xu J. Impact of advanced hearing aid technology on speech understanding for older listeners with mild to moderate, adult-onset, sensorineural hearing loss. Gerontology 2014;60:557-68.

2 Barker F, Mackenzie E, Elliott L, et al. Interventions to improve hearing aid use in adult auditory rehabilitation (Review). Cochrane Database Syst Rev 2014;(7):CD010342.

3 Nishimura T, Hosoi H, Saito O, et al. Benefit of a new hearing device utilizing cartilage conduction. Auris Nasus Larynx 2013;40:440-6.

4 Haynes DS, Young JA, Wanna GB, Glasscock ME. Middle ear implantable hearing devices: an overview. Trends Amplif 2009;13:206-14.

5 Bittencourt AG, Burke PR, Jardim Ide S, et al. Implantable and semi-implantable hearing AIDS: a review of history, indications, and surgery. Int Arch Otorhinolaryngol 2014;18:303-10.

6 Colletti V, Soli SD, Carner M, Colletti L. Treatment of mixed hearing losses via implantation of a vibratory transducer on the round window. Int J Audiol 2006;45:600-8.

7 Colletti L, Mandala M, Colletti V. Long-term outcome of round window Vibrant SoundBridge implantation in extensive ossicular chain defects. Otolaryngol Head Neck Surg 2013;149:134-41.

8 Baumgartner W-D, Boeheim K, Hagen R, et al. The Vibrant Soundbridge for conductive and mixed hearing losses: European multicenter study results. Adv Otorhinolaryngol 2010;69:38-50. 